ISSN 00156043

\title{
NOTAS
}

\section{El principio ético y la crisis de 2008: hacia una reorga- nización del sistema}

\section{Luis Orduna Díez'}

Resumen: El autor invoca el "principio ético", entendido como lo esencial en el carácter social del hombre y como condición fundamental de la conducta humana que obliga a todos los hombres a obrar conforme a la "justicia según la recta razón". La "recta razón" suministra "normas de conducta" susceptibles de validez general en sus aplicaciones prácticas y confiere a todos los seres humanos una "capacidad de juicio" común a todos ellos. El "principio ético" eleva a todos los seres humanos a una categoría superior a todo lo creado que confiere a cada persona una "igual dignidad"; ambos proporcionan luz para juzgar la realidad social de nuestro tiempo y para discernir sobre las diversas situaciones que pueden producirse en relación con la aplicación y cumplimiento de los Derechos Humanos, especialmente en los momentos más graves que afloran cíclicamente en el sistema capitalista mundial: las "crisis cíclicas". Sentadas las anteriores premisas, el autor analiza brevemente las causas de la "crisis económica actual" en sus aspectos conceptuales e históricos. A continuación, plantea lo que considera algunas propuestas fundamentales para la reorganización del sistema de convivencia e insiste, finalmente, en lo que considera reformas urgentes, sobre la estructura de la empresa, incluida la bancaria, sobre el problema de los precios y sobre un potencial orden constitucional mundial, que ha de ser instituido como una verdadera democracia universal.

Palabras clave: Principio ético, recta razón, reglas de conducta, capacidad de juicio, igual dignidad, derechos humanos, orden económico.

Fecha de recepción: 9 de mayo de $201 \mathrm{l}$.

Fecha de aceptación definitiva: 29 de septiembre de $201 \mathrm{I}$.

' Catedrático de Estructura e Instituciones Económicas de la Universidad Complutense de Madrid. 


\section{Ethical principles and the 2008 crisis: moving towards a reorganisation of the system}

\begin{abstract}
The author invokes "ethical principles", these being understood as the essential feature in the social nature of man and as a fundamental condition of human behaviour which require all men to act according to "justice" based on "right reason"." "Right reason" provides "rules of conduct" capable of general validity in practical applications, and gives human beings a shared "capacity of judgement". "Ethical principles" raise all humans to a higher level compared to any other beings, thus bestowing "equal dignity" on each person. "Ethical principles" and "equal dignity" both shed light on the social reality of our times and help to discern the variety of situations that can arise from the application and fulfilment of Humans Rights, especially at this critical moment that emerges cyclically in the global capitalist system: the "cyclical crisis". Having established the above assumptions, the author briefly analyses the causes of the "currenteconomic crisis", focusing on conceptual and historical aspects. Then he presents some of what he considers to be key proposals for reorganising the system of coexistence, and finally, the author highlights those reforms considered most urgent with respect to business models, including the banking system, and also the regulation of prices and the need for establishing a new constitutional world order, which must be instituted as a true universal democracy.
\end{abstract}

Key words: Ethical principle, right reason, rules of conduct, capacity of judgement, equal dignity, human rights, economic order.

\section{Le principe éthique et la crise de 2008: vers une réorganisation du système}

Résumé: L'auteur invoque le "principe éthique", le considérant comme l'essentiel dans le caractère social del'homme et comme la condition fondamentale de la conduite de l'être humain qui oblige tous les hommes à agir conformément à la «justice selon la droite raison». "La droite raison» fournit des «normes de conduite» susceptibles d'être valables $d$ 'une manière générale dans ses applications pratiques et confère à tous les êtres humains une "capacité de jugement» commune à eux tous. Le "principe éthique» élève tous les êtres humains à une catégorie supérieure à tout ce qui est créé et confère à chaque personne une "même dignité». Toutes deux permettent de juger la réalité sociale de notre temps et de discerner selon les situations diverses qui peuvent se produire en relation avec l'application et le respect des Droits del'Homme, spécialement dans les plus graves moments que affleurent cycliquement dans le système capitaliste mondiale: les "crises cycliques». Le point de départ fixé, l'auteur analyse brièvement les causes de la «crise économique actuelle» dans ses aspects conceptuels et historiques. Ensuite, il énonce ce qu'il considère quelques propositions fondamentales pour la réorganisation du système de coexistence et insiste, finalement, dans ce qu'il considère des réformes urgentes sur la structure de l'entreprise, en incluant les banques, sur le problème des prix et sur un hypothétique ordre constitutionnel mondial, qui doit être investi comme une véritable démocratie mondiale.

Mots clés: Principe éthique, droite raison, règles de conduite, capacité de jugement, égale dignité, Droits de l'Homme, ordre économique. 


\section{Introducción}

Con motivo de la crisis económica actual se ha puesto de manifiesto la notoria ausencia de ética en las conductas dominantes del "sistema económico mundial". Esto ha levantado distintas voces que claman por una reorganización del modelo para que la ética de las conductas humanas esté presente en todo momento.

No obstante, para llegar a una correcta reorganización del modelo, es preciso primero realizar un correcto diagnóstico de los problemas y estudiar la correlación de los mismos con los principios que rigen la "ciencia económica académica". Tras haber averiguado las verdaderas causas de los problemas, se podrán implementar las reformas más adecuadas para corregir las fluctuaciones cíclicas capitalistas y las crisis inherentes a dichas fluctuaciones, (incluida la actual) tratando de evitar su reiteración.

Para su análisis y desarrollo, voy a dividir el tema en tres partes.

En primer lugar, me referiré al principio ético de las conductas, del que deriva el principio de libertad y el de dignidad, así como los derechos y deberes humanos fundamentales que han de estar en la base del orden social, político y económico, así como en el núcleo de las estructuras e instituciones de la convivencia, tratando de aclarar si efectivamente están vigentes o no.

En segundo lugar, me voy a referir al diagnóstico de la crisis económica actual, en cuanto a sus aspectos fundamentales. Para ello partiré de un análisis de las causas estructurales o más profundas que están en el origen de todas las crisis y fluctuaciones económicas, así como también a las causas circunstanciales o desencadenantes de cada crisis en particular, según el momento histórico de que se trate.

Y, en tercer lugar, haré referencia a las líneas generales, de lo que podríamos considerar posibles reformas, las cuales habrían de ser implementadas de cara a una reorganización del sistema, a todas luces necesaria, señalando las medidas básicas a tomar, su justificación y el camino por donde estas reformas podrían empezar. 


\section{El principio ético y la Declaración Universal de Derechos del Hombre proclamada por la ONU en 1948}

Con el fin de establecer la relación que guarda o debe guardar el principio ético de las conductas con el orden económico, debemos, en primer lugar, aclarar a qué nos referimos con el concepto de "principio ético de las conductas".

\section{I. El principio ético de las conductas: su concepto}

Cuando hablamos del "principio ético de las conductas" queremos referirnos al hecho de que la conducta humana guarda y ha de guardar siempre una íntima relación con la "capacidad racional" que corresponde a los seres humanos. Como es sabido, la capacidad racional tiene una doble dimensión, que se expresa en el concepto tomista de "libre arbitrio", el cual comprende tanto la condición de la "libertad" como la "capacidad de discernimiento".

En este sentido partimos de un alto concepto de la libertad porque la "libertad humana" ha de tomarse como una de las notas características más excelsas de nuestra condición de personas, que nos diferencia de cualquier otro ser conocido, elevando nuestra dignidad al máximo rango y confiriéndonos un gran "poder". Ahora bien este poder no puede ser arbitrario, sino que está orientado por la razón. Así, en efecto, para el filósofo E. KANT (siguiendo a G. VECCHIO, 1969, p. 96) en el primer estrato de nuestra capacidad racional está el "principio del deber". Según Kant, este principio es la mayor certeza que poseemos, algo de lo que no podemos dudar. Es una especie de "voz interior y sublime" que impone respeto, que nos amonesta invenciblemente aunque queramos hacerla callar o tratemos de no escucharla. Kant explica que el "deber", es incluso anterior a la "libertad", ya que ésta no podría concebirse sin que previamente existiera una "capacidad de discernimiento" vinculada al "deber", tanto en lo que se refiere a nuestros pensamientos e "intenciones" como en lo que afecta a nuestras "obras".

La "capacidad de discernimiento" se une así a nuestra "libertad" para determinar nuestras "decisiones". De estas tres dimensiones deriva la "conciencia", que está vinculada al saber, al poder y al querer, por virtud de todo lo cual los seres humanos somos "plenamente responsables" de nuestros "actos". La "conciencia", de un modo inexorable e invencible, nos invita a obrar según el bien ly lo que es mejor) conforme al principio del deber, al tiempo que nos propone rehuir el mal y lo que no es conforme al deber. En definitiva la "conciencia" nos suministra una "capacidad de juicio" que es común a todas las personas y nos indica lo que 
está bien y lo que está mal, lo que es mejor y lo que es peor, lo que es bueno y lo que es malo, etc. $y$, en este sentido, lo que es correcto y lo que es incorrecto. La "conciencia" nos suministra también una "máxima de conducta", que es la que debe inspirar nuestras acciones y que consiste en hacer a los demás todo aquello que nos gustaría que los demás nos hicieran a nosotros [IGLESIA CATÓLICA ( I C), 1992, p. 406, (Mt. 7, 12; cf. Lc. 6, 31; Tb. 4, 15)], o visto a la inversa, no hacer a los demás aquello que no nos gustaría que los demás nos hicieran a nosotros. El filósofo Kant expresa esta idea de otro modo, afirmando el "imperativo categórico" que dice: obra de tal manera que la máxima de tu acción pueda servir como base de una legislación universat?

En consecuencia, el "principio ético de las conductas", de un modo acorde con la "razón", hace a todos los seres humanos "iguales en dignidad". Y esta "igual dignidad", común denominador de todos, se convierte en el principio fundamental de nuestra civilización, de donde dimanan todos los demás deberes y derechos humanos.

\subsection{La Declaración Universal de Derechos del Hombre de la ONU}

Precisamente, la proclamación de estos derechos y deberes fundamentales fue ya formulada de una manera expresa por la Organización de Naciones Unidas, el 10 de diciembre 1948, en una Conferencia celebrada en París. En esta Proclamación se enunciaron 30 derechos humanos fundamentales, entre los cuales, aparecen cuatro que interesa resaltar ahora por su carácter estrictamente económico. Sin embargo, como veremos, ninguno de estos cuatro derechos de carácter económico

\footnotetext{
2 Dice G.VECCHIO, que: En la 'Crítica de la razón práctica', Kant refuta ante todo, los sistemas de moral fundados sobre la utilidad o sobre la búsqueda de la felicidad (eudemonismo). La moral se distingue radicalmente de la utilidad y del placer. Manda de modo absoluto;... quiere que nuestros actos tengan un carácter universal. A esto se reduce la ley moral, que Kant denomina: 'imperativo categórico', y que formula como sigue: "Obra de tal manera que la máxima de tu acción pueda valer como principio de una legislación universal". Vecchio prosigue: Esto significa que nuestra acción no debe ser motivada por impulsos particulares; que no debe haber contradicción entre nuestra acción individual y lo que debe ser norma para todos... No dice lo que se debe hacer, sino como y con qué intención se debe obrar. Según tal principio precisa obrar con y por la conciencia del deber, de modo que sea posible una legislación universal conforme a la acción particular. Y concluye: Adviértase que Kant no afirmó nada verdaderamente nuevo con su teoría; la ley moral formulada por él no es substancialmente diversa de las enseñanzas de los pensadores antiguos y en especial de la doctrina cristiana. ... El mismo Kant, cuando se le hizo notar la escasa novedad de su idea de la ley moral, se mostró muy satisfecho de ello, porque le hubiera parecido extraño inventar una nueva moral, como si ésta no hubiese sido siempre la misma, sentida de modo igual para todos. [G. VECCHIO, 1969, (p.96)].
} 
fundamental se aplican en ningún país, ni siquiera en los que se llaman a sí mismos democráticos y países desarrollados. Concretemos esta cuestión con más detenimiento:

El primero de estos artículos es el 13, que dice, en cita textual:

Toda persona tiene derecho a circular libremente y a elegir su residencia en el territorio de un Estado... tiene derecho a salir de cualquier país, incluso del propio y a regresar a su país.

Como es obvio, este derecho se refiere al principio de "libre circulación de personas" y está estrechamente ligado al problema gravísimo de la "emigración", el cual, a su vez, guarda íntima relación con el orden económico establecido, tanto en el ámbito nacional como en el ámbito internacional. A nadie se le escapan las múltiples razones por las cuales el principio de libre circulación de personas y trabajadores no se cumple ni puede cumplirse hoy en día en ningún país del mundo, mientras no cambie la "estructura económica mundial" 3 . Un cambio que debería estar dirigido a que todos los países tuvieran su propia oportunidad de "desarrollo" dentro de un "orden universal justo". Se trataría pues de un derecho humano fundamental que, hoy, no está vigente ni es respetado en prácticamente ningún país del mundo, incluidos los más ricos o desarrollados que son, como todo el mundo sabe, los que más trabas ponen a la "libre circulación de personas" ${ }^{4}$.

En segundo lugar, el artículo 21 afirma que:

Toda persona tiene derecho a participar en el gobierno de su país directamente o por medio de representantes libremente elegidos.

Es decir, estamos ante el principio de la "participación democrática", que ha de estar en la base de todas las democracias. Sin embargo, la democracia hoy ha sido adulterada, porque se ha suplantado la participación por la representación, como si fueran la misma cosa, cuando no lo son. Las actuales democracias occidentales son auténticas oligarquías. Se puede decir que, hoy, los llamados gobiernos

\footnotetext{
${ }^{3}$ El lector interesado en las cuestiones estructurales que afectan a la economía mundial, puede consultar mis libros titulados: Estructura económica y desarrollo: El tránsito hacia una reorganización del sistema, 2011-b, CERSA, (pp. 91-250); e Historia económica del siglo XX: Integración europea e integración mundial, 2011-a, CERSA, (pp. 417-530).

${ }^{4}$ Para una profundización en el problema de la emigración internacional y sus posibles soluciones, puede verse L. ORDUNA, $2011-a$, (pp. 422-432).
} 
democráticos constituyen la expresión de una pseudo-democracia siempre gobernada por los mismos. Por eso, necesitamos un nuevo orden político y económico (y también jurídico), establecido sobre la base de una mayor participación directa y una menor representación de los partidos políticos. Las cuestiones relativas al orden democrático son fundamentales para la organización económica, dadas las íntimas relaciones que existen entre realidad política y realidad económica ${ }^{5}$. Por otra parte, la "corrupción política" de los llamados a sí mismos países democráticos, está tan extendida que ha llevado a que una gran masa de la población de estos países no se considere representada por sus mandatarios políticos. Precisamente, a causa de la falta de una "auténtica democracia participativa", ha surgido ya un "movimiento mundial" de "indignación"6 que trata de luchar pacíficamente contra las estructuras políticas y oligarquías pseudo-democráticas que gobiernan el mundo 7 .

Por su parte, el artículo 23 de la Declaración Universal de Derechos del Hombre de la ONU, afirma que:

Toda persona tiene derecho al trabajo, a la libre elección de su trabajo a condiciones equitativas y satisfactorias de trabajo y a la protección contra el desempleo>>. Y prosigue: $\ll$ YY tiene derecho, sin discriminación alguna, a igual salario por trabajo igual $>>y,<<\ldots a$ una remuneración equitativa y satisfactoria que le asegure, así como a su familia, una existencia conforme a la dignidad humana y que será completada, en caso necesario, por cualesquiera otros medios de protección social, etc.

El "derecho fundamental al trabajo" es el derecho humano mas importante para la "estructura económica" de cualquier país. Su transcendencia deriva del hecho de que, si cada individuo tiene "derecho a la vida", ha de tener "derecho a una oportunidad concreta de trabajo" pues, en caso contrario, en la medida en la cual el que no trabaja no puede ganar el sustento para sobrevivir, el sujeto quedaría condenado a morir por inanición, sobre todo cuando la sociedad está organizada bajo un modelo económico de alta especialización donde, además, el "principio

\footnotetext{
${ }^{5}$ No es ahora tampoco el momento de tratar en profundidad las cuestiones relativas a la vigencia, o no, de la democracia. Sin embargo, de esta cuestión he tenido ocasión de ocuparme con detenimiento en otro trabajo, a cuya lectura invito al lector interesado. Puede verse L. ORDUNA, 2010-a, (pp. 218-301).

6 Para más información sobre este movimiento puede consultarse <<www.elindignado.com $>$.

${ }^{7}$ A las cuestiones interdisciplinarias que relacionan la política con la ciencia económica y con la democracia y el "estado de derecho" he tenido ocasión de referirme en mi obra: Economía y Antropología ética: El problema interdisciplinario de las ciencias sociales, 2010-a, CERSA, (185-315), a cuya lectura remito al lector interesado, especialmente, la de los capítulos 7 y 8 .
} 
ético de las conductas" es el gran ausente de la organización del sistema y de la filosofía que lo inspira, como veremos en detalle un poco mas adelante ${ }^{8}$.

Y, por último, el artículo 28 de la Declaración, que dice:

Toda persona tiene derecho lobsérvese la extraordinaria importancia de lo que aquí se afirma) a que se establezca un orden social e internacional en el que los derechos y libertades proclamados en esta Declaración se hagan plenamente efectivos .

He aquí, pues, la primera obligación del Estado y de todos los Estados, que consiste en la "perentoria obligación de coordinarse" con los demás para hacer efectivo en el ámbito nacional e internacional la "plena vigencia de estos derechos fundamentales" en todas partes por igual. A nadie se le escapa que estamos muy alejados de que los Estados cumplan esta imperiosa obligación y, sin embargo, ya han pasado más de 60 años desde que se promulgó este derecho como obligación fundamental de los estados y gobiernos.

Sobre el juicio que nos ha de merecer este estado de cosas, nuestra posición no puede ser más condenatoria. Téngase en cuenta que basta con que no se cumpla uno sólo de estos derechos, para que todo el sistema de derechos fundamentado en la "dignidad humana", haga agua y el barco de la convivencia se hunda. No estamos hablando de unos derechos cualesquiera, sino de "derechos humanos fundamentales", o lo que es lo mismo, derechos que al dimanar directamente de la dignidad humana, son "anteriores" al Estado.

Los derechos humanos fundamentales "no dimanan del Estado" como a veces se nos ha pretendido hacer creer por los partidos políticos o por ciertos dirigentes inmorales y sin escrúpulos. Dimanan directamente de la "dignidad de la persona" y de la "ley natural", insita en nuestra mente. El Estado en ningún caso puede contradecir estos derechos, sino que, incluso, la propia legitimidad de la existencia del Estado" deriva precisamente de su aplicación efectiva, de tal modo que, si el Estado infringe esta obligación, su propia existencia y su autoridad quedan "deslegitimadas" y el propio Estado y sus estructuras se convierten en instrumentos de una "tiranía".

No obstante, lo más grave de la situación es que estos derechos no se cumplen

\footnotetext{
${ }^{8}$ Sobre los errores al uso en la definición de ciencia económica convencional y sobre los errores de concepto que tradicionalmente han inspirado la organización del mundo capitalista, me remito a lo ya expuesto en mi trabajo sobre: Ciencia económica y escasez: clarificación de conceptos> L. ORDUNA, 2010-c, (pp. 101-116).
} 
hoy en día en ningún país del mundo. Y, en este sentido, se puede afirmar que la "principal tarea pendiente" de la sociedad y de las ciencias sociales, políticas, económicas y jurídicas, consiste en transformar las estructuras organizativas de la convivencia para hacer efectiva la vigencia de estos derechos.

Con esto, llegamos a la segunda cuestión que habíamos señalado, relativa al diagnóstico de las crisis y de las fluctuaciones económicas en general para, inmediatamente después, prestar especial atención a la crisis del momento actual.

\section{Breve diagnóstico de las crisis y fluctuaciones económicas}

Antes de analizar la crisis de 2007-2008 conviene aclarar el concepto mismo de crisis económica en el modelo capitalista y las causas que motivan la aparición de estas crisis.

\section{I. ¿Qué son las crisis y fluctuaciones económicas?}

En general, las "crisis económicas" pueden conceptuarse como la fase álgida de ciertas convulsiones graves de la actividad económica, que se repiten periódicamente en el sistema capitalista.

Estas convulsiones constituyen un problema endémico y reiterativo que se conoce también como lo que los economistas llamamos "ciclos" o también "fluctuaciones económicas". Es frecuente denominar a las fluctuaciones por el nombre de la crisis determinada que la caracteriza o le da nacimiento. Este nombre suele coincidir con el del año del momento en que tuvo lugar la fase álgida de la convulsión (así se habla de la Gran depresión de 1929, o también crisis del 29, para denominar al ciclo depresivo de la década de los años treinta del siglo pasado).

Lo importante es observar que las fluctuaciones tienen siempre un carácter de oscilación grave de la actividad productiva. Estas oscilaciones cuentan con distintas fases, de duración indeterminada y variable. En toda fluctuación económica podemos distinguir, al menos, cinco fases: 1.- la fase álgida o crisis propiamente dicha, en la que el ciclo estalla y se vuelve relativamente incontrolable o ingobernable; 2.- la fase de descenso, que se suele caracterizar por una profundización de la insuficiencia de la demanda; 3.- la fase más baja de la recesión o depresión, caracterizada por el "paro masivo"; 4.- la fase del estancamiento productivo 
(cuya duración puede ser muy variable, dependiendo de múltiples circunstancias); y 5.- la fase de recuperación que, generalmente aparece vinculada a cambios estructurales en la organización" del sistema y, cuya rapidez o lentitud, depende del acierto o no en las medidas de política económica implementadas por las autoridades públicas.

Las oscilaciones económicas que caracterizan a las fluctuaciones afectan a todas las variables económicas fundamentales (precios, salarios, inversión, endeudamiento público y privado, tipos de interés, crédito, demanda efectiva, tipos de cambio, cantidad de dinero en circulación, gastos e ingresos públicos, flujos internos e internacionales de capitales, relaciones de comercio, etc.).

Por su naturaleza convulsiva, todas las crisis y fluctuaciones económicas producen un movimiento interno del sistema de producción y del sistema de distribución de la renta y la riqueza que se manifiesta en múltiples desequilibrios. Quizás, sin embargo, lo más importante, son los "efectos finales" que las crisis y fluctuaciones producen. Entre estos, destacamos los siguientes:

1. una reducción drástica del volumen de ocupación y empleo,

2. una variación sustancial de la distribución de la renta y de la riqueza de carácter arbitrario, entre los distintos sujetos y grupos sociales que suele afectar más duramente a las capas sociales más débiles,

3. un empobrecimiento social considerable de la masa de población (consumidores y trabajadores), $y$,

4. en términos internacionales produce un agravamiento del bache de renta y riqueza que separa al tercer mundo del primer mundo o, dicho en términos más generales, agrava el bache de poder que separa a los más fuertes de los más débiles.

Todos los ciclos no son iguales, sino que cada ciclo es diferente porque la historia, contrariamente al aforismo vulgar, no se repite, sino que la historia es siempre distinta con arreglo a las circunstancias del momento particular. Y, en este sentido, el carácter reiterativo de las fluctuaciones, nos hace recordar que es evidente

\footnotetext{
${ }^{9}$ Al lector interesado en el estudio de las crisis y fluctuaciones económicas del siglo XX le sugiero la lectura de mi libro Historia económica del siglo XX: Integración europea e integración mundial, 2011 -a, CERSA, (capítulos 2 a 8 , inclusive).
} 
que existe una causa común a todas ellas. Si no hubiera una causa común, no se reiterarían este tipo de convulsiones de la actividad económica. Por eso, lo importante es observar que, detrás de lo aparente, subyacen unas causas profundas que son siempre las mismas. Nosotros, a estas causas, las hemos llamado "causas estructurales".

Y, junto a ellas, aparecen otras causas, que podemos llamar "causas circunstanciales" o "desencadenantes", que tienen que ver con el momento particular histórico en el que se produce o se desencadena la crisis.

\subsection{Causas estructurales de las crisis y fluctuaciones económicas}

Entre las causas estructurales de las crisis y fluctuaciones, pueden encontrarse tres que consideramos más relevantes. Serían las siguientes:

\section{$I^{\text {a }}$. La filosofía del lucro máximo}

La primera causa sería de tipo "filosófico" y consistiría en lo que llamamos "espíritu de lucro máximo".

El espíritu de lucro que impera en el sistema capitalista (el modo de organización mundial en el que vivimos, desde el punto de vista económico) responde a una "filosofía hedonística" que se denomina, "filosofía del interés propio exclusivista".

Esta filosofía está acuñada en la ciencia económica como el móvil fundamental de las conductas económicas. Para ello se ha erigido un estereotipo del ser humano, que se denomina en la filosofía, "homo oeconomicus", el cual tiene como característica fundamental, que el móvil de todas las conductas económicas humanas ha de ser el "interés propio exclusivista"

La figura del "homo oeconomicus" ha sido diseñada por los autores clásicos y neoclásicos de la ciencia económica, fundamentalmente por el que se considera padre de la ciencia económica moderna, Adam Smith. En su obra fundamental sobre La naturaleza y causas de la riqueza de las naciones, Adam Smith nos habla precisamente de lo siguiente, en cita textual:

Aunque cada sujeto busca su propio interés, tratando de hacer máximo el valor de su capital... y en verdad no intenta promover el bien común o interés público de ningún modo... sino que busca sólo su propia seguridad... sólo su propia ganancia,... lo cierto es que, 
en este proceso, es guiado como por una mano invisible $y$, sin darse cuenta, contribuye a alcanzar el bien de la sociedad, ... de modo que, buscando exclusivamente su propio interés, continuamente promueve el de la sociedad de una manera más efectiva que si esto hubiera entrado en sus propósitos e intenciones. (Traducción propia del original, $A$. SMITH, 2005, pp. 363-365).

Ante tal aserto uno se queda perplejo. ¿्Puede ser verdad? Pues no, no es verdad. Es falso. Y, lamentablemente, estas afirmaciones constituyen la columna vertebral, en la que se ha pretendido apoyar el modelo capitalista y el tipo de organización económica mundial en el que hoy vivimos.

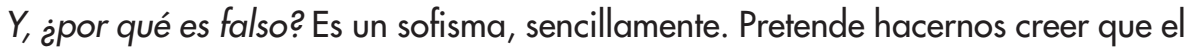
bien común y el interés general de la sociedad se alcanzarán de una forma más efectiva si todos y cada uno de los sujetos buscan exclusivamente su propio interés, con exclusión del bien común, que si incluyeran el bien común, de un modo compatible con la búsqueda del interés propio legítimo, en sus decisiones.

La teoría de Smith es también un "maniqueísmo", que pretende llegar a un orden social sin una jerarquía de principios, fundamentándose sólo en la "ley de la oferta y la demanda", ajena al principio del bien y del mal y ajena a la "ley natural".

A partir de esta base, Smith construye una serie de teoremas que constituyen, según él, la base del orden social. Un orden social caracterizado por confiar la regulación de la realidad económica y la solución de todos los problemas económicos al "automatismo del mercado", con la consiguiente "inacción gubernamental". Con la visión de Smith, el concepto de escasez y la ley de la oferta y de la demanda, en un contexto de lucha competitiva para obtener lucro máximo individual con carácter exclusivista, ha pasado a constituirse en el teorema central de la ciencia económica académica y convencional, más ortodoxa ${ }^{10}$.

Pero, la consecuencia de haber establecido un orden económico mal fundamentado (por razón de sus crasos errores conceptuales), ha sido que el sistema mundial erigido no sirve para dar solución a los "problemas económicos fundamentales". Así, hemos llegado hoy a un orden social y económico, político y jurídico caracterizado por el hambre, la pobreza, el desempleo, el subdesarrollo, las crisis cíclicas, el crecimiento asimétrico, la especulación exagerada, la falta de eficiencia en el uso

\footnotetext{
10 Sobre el error básico de Adam Smith, el subsiguiente paradigma neoclásico y las doctrinas convencionales de la escuela ortodoxa actual así como las pretensiones subyacentes a todo ello, sugiero la lectura de mi trabajo anteriormente citado sobre < Ciencia económica y escasez: clarificación de conceptos>. L. ORDUNA, 2010-c, (pp.104 a 107).
} 
de las tecnologías para los fines del desarrollo y humanitarios, y, en definitiva, la falta de equidad en la distribución de la renta y de la riqueza que afecta a más de dos tercios de la humanidad.

\section{$2^{\mathrm{a}}$. La praxis de un poder arbitrario y desigual}

La segunda causa estructural sería de tipo "pragmático" y consistiría en el "injusto y arbitrario poder de influencia" de los distintos agentes económicos sobre los mercados.

Este tipo de poder tiene su origen en complejas razones, unas de carácter propiamente "estructural" y otras de carácter estrictamente "histórico".

Las razones estrictamente históricas relativas a la configuración del poder real actual ejercido por los distintos agentes en los mercados y en la sociedad resultan muchas veces difíciles de aclarar, aunque su aclaración nunca es imposible. Son fruto y resultado de múltiples hechos históricos que se caracterizan por su complejidad. "A posteriori" la historia es la que es y sus hechos no pueden cambiar. Sin embargo, dados los hechos, si puede explicarse porqué la historia ha sido de una determinada manera y no de otra y porqué su evolución pudo haber sido distinta si los hechos y decisiones humanas hubieran discurrido de otro modo distinto y más racional, que como lo hicieron.

Esta forma de razonar, concerniente a la averiguación de la configuración histórica de la "estructura de poder real" actual, enlaza directamente con las características propiamente "estructurales" de dicho poder real y del poder humano en toda su extensión, vistos tanto de un modo retrospectivo como de un modo prospectivo y tanto en lo que concierne al poder en el "fuero interno" de cada sujeto como en el "fuero externo".

De ahí que la realidad del actual "sistema de poderes fácticos" y de su proceso de configuración, pueda ser aclarado mediante un juicio sobre la cultura y la filosofía que informa cada sistema de convivencia, en cuyo seno vivimos y sobre el cual hemos de actuar. No se olvide que la organización de este sistema de convivencia, es siempre obra humana $y$, por consiguiente, tal organización, igual que ha sido constituida por el hombre, puede ser cambiada y mejorada en el proceso histórico de cara al porvenire, incluso, puede ser reconstruida de un modo global, partiendo de una conceptuación paradigmática y filosófica más racionalmente elaborada. 


\section{$3^{\text {a }}$. La estructura organizativa e institucional del sistema}

Así resulta que, junto a la causa filosófico-estructural del lucro máximo y la causa pragmática de los poderes fácticos, encontramos una tercera causa determinante de las crisis y fluctuaciones, que es de carácter "institucional".

Consiste precisamente en caer en la cuenta de cuál es la "estructura organizativa" del "sistema de convivencia" en sus diversas dimensiones, política, económica, jurídica, educativa, psico-social, etc., y ver cuál es la forma de transformar esa estructura con vistas a reconstruirla y mejorarla, sobre la base de un modelo paradigmático más racionalmente elaborado.

Como ya hemos dicho, el análisis de la realidad actual, nos lleva a descubrir que nos hallamos inmersos en la estructura de un "sistema de convivencia predominante", que conocemos como "sistema capitalista" y cuyo paradigma fundamental está constituido por el "modelo de la perfecta competencia", deducido directamente de la "filosofía de Adam Smith" sobre el "interés propio exclusivista" antes mencionado.

Por lo tanto, podemos afirmar que la filosofía del "interés propio exclusivista" como móvil de todas las conductas, bajo una "estructura de poder" históricamente acumulada, de carácter arbitrario y desigual, determina sobre la base del "sistema organizado", en forma de "libertad competitiva" modulado por la ley suprema de la "oferta y la demanda"11, una "nueva desigualdad estructural del poder", de carácter arbitrario y desigual que se acumula a la anterior. Y éste es, sencillamente, el "mecanismo fundamental" que subyace en "todas" las "crisis y fluctuaciones económicas".

\footnotetext{
11 A mi juicio, el error fundamental de las tesis de L. RoBBINS (1952) sobre el concepto de ciencia económica y, también, el de los autores de la doctrina convencional, con sus paradigmas clásicos y neoclásicos, consiste en haber instituido la "escasez" como el nudo gordiano de lo económico, haciendo caso omiso del concepto de "progreso". Esta opción de la doctrina convencional significa querer aferrarse a las estructuras del pasado, negando toda posibilidad de abrirse a los posibles cambios en la organización del sistema subyacente. Pero lo cierto es que el núcleo esencial de lo económico está en el progreso y no en la escasez. Así, en efecto, como ya he tenido ocasión de publicar en otro trabajo reciente, si la doctrina hubiera instituido el "progreso" como la esencia de lo económico, hubiéramos podido abocar a un "sistema" en el que la "competitividad" hubiera podido ser sustituida por la "cooperación", el "lucro" por el "beneficio creativo", los "abusos de poder" (con "paro masivo") por la "eficiencia equitativa" (con "pleno empleo") y la "arbitraria y desigual distribución de la renta y de la riqueza" por la "justa distribución de los beneficios". Con la consecuencia de que el sistema podría mejorar su "eficiencia integral" en beneficio de todos y cada uno de los sujetos sociales. Véase L. ORdUNA, 2010-c, (p. 109).
} 
Pero este mecanismo trae como consecuencia "tres nuevos desequilibrios", de "carácter real".

1. En primer lugar, el que tiene lugar en el "sistema de fijación de los precios", como consecuencia de los poderes desiguales que intervienen en los mercados. Nos encontramos, así, con paradojas como que mientras un futbolista de primera fila ingresa más de seiscientos millones de euros al año (según dice la prensa deportiva), un científico capaz de inventar algo que salva miles de vidas humanas ingresa menos de sesenta mil euros anuales, esto es, menos de una diezmilésima parte.

2. En segundo lugar, el que tiene lugar en el "sistema de la contratación" en general y particularmente en el sistema de "contratación del trabajo" por el capital, organizado en forma de sociedad anónima o limitada y el sistema de contratación en los mercados (bajo la lucha competitiva) ${ }^{12}$.

3. Y el que, finalmente, como consecuencia de los desequilibrios anteriores, tiene lugar en el ámbito de la "distribución de la renta y de la riqueza" en sus distintos niveles, sistemas y sub-sistemas, nacionales e internacionales ${ }^{13}$.

${ }^{12}$ En mi trabajo publicado bajo el título Ciencia económica y escasez: clarificación de conceptos, he tenido ocasión de manifestar lo siguiente: La pretensión capitalista de supeditar el trabajo al capital ha llegado al extremo de querer hacer del trabajo un "apéndice del capital". Pretensión que ha sido conseguida y, además, ha sido sacralizada por el "derecho positivo mercantil" de modo totalmente injusto. Esta injusticia se manifiesta especialmente en el "estatuto jurídico-económico de la sociedad de capital", que ha suplantado al "estatuto de la empresa", como si ambos conceptos ("sociedad de capital" y "empresa") fueran la misma cosa. De este modo la "sociedad de capital" ha subvertido el sistema lógico, apropiándose de modo asimétrico, de todos los excedentes generados con el esfuerzo común del trabajo y del capital, en el seno de la empresa, asumiendo todas las facultades decisorias, excluyendo de ellas totalmente al trabajo y, acumulando, finalmente, ganancias excesivas o abusivas, en detrimento de las que debieran haberse atribuido a la clientela y al trabajo. Véase L. ORDUNA, 2010-c, (pp. 109-110).

${ }^{13}$ La organización capitalista hace caso omiso del objetivo esencial a que todo sistema económico viene llamado y que consiste en facilitar a todos los sujetos un "empleo", que garantice la supervivencia de cada cual y le dote de una "igualdad de oportunidades" respecto a los demás sujetos. La consecuencia de la "falta de primacía" del trabajo sobre el capital está, en que el sistema capitalista resultante ha sustituido el "objetivo del pleno empleo", por el "poder de los monopolios y los grupos económicos", instituidos así en controladores del ámbito institucional del sistema. En este sentido, podemos reiterar que La organización capitalista resultante ha soslayado el modo lógico de "fijación de los precios" que derivaría de una recta valoración de los bienes y servicios en forma de "escandallos" conducentes a obtener el "precio justo", de una manera objetiva. Con este fin, la correcta valoración ha sido sustituida por un método de fijación de precios basado en la competitividad y el lucro, a partir de poderes desiguales de influencia sobre el mercado bajo la ley de la oferta y la demanda, que opera para los 
A estos tres "desequilibrios" se añaden otros "tres adicionales de carácter financiero", que son:

1. El que se produce en el sector público, cuando está mal administrado (exceso de endeudamiento público y déficit público, despilfarros en inversiones improductivas, corrupción, etc).

2. El que, normalmente, afecta a la estructura del sector exterior en el terreno real $y$ en el terreno financiero (y tanto a corto como a largo plazo), como consecuencia de la desigualdad de poder de los grupos económicos y empresariales dominantes de los mercados, en una escala global.

3. El que tiene lugar en el sector bancario, cuando aparecen desequilibrios de liquidez, solvencia o rendimiento en la administración de los activos y los pasivos bancarios, normalmente debido al exceso de afán lucrativo o especulativo de los propios bancos (entidades eminentemente lucrativas, no se olvide) sin tener en cuenta las normas de la correcta administración bancaria.

La banca tiene siempre un gran poder y puede acentuar todos los desequilibrios anteriores mediante el "proceso de expansión múltiple de los activos y pasivos bancarios" ${ }^{\prime 14}$. De este modo, bien por cuenta propia bien suministrando crédito a los sujetos que operan en los mercados, la banca contribuye muy activamente a generar estos desequilibrios, a través del llamado "apalancamiento", que básicamente consiste en un proceso de actuación especulativa en los mercados, materializado en forma multiplicativa mediante el crédito a favor de los especuladores. Más adelante nos volveremos a ocupar de estas cuestiones.

Una vez analizadas las que he llamado "causas estructurales", pasemos al análisis de las "causas circunstanciales" o "desencadenantes" de las crisis y fluctuaciones económicas.

intercambios de toda clase de bienes y servicios, incluido al trabajo, considerado a estos efectos como una mercancía. Se constituye así un método que refuerza la "primacía del capital sobre el trabajo", que estaba en el origen conceptual de los errores capitalistas. Véase L. ORdUNA, 2010-c, (pp. 109-110).

${ }^{14}$ De estas cuestiones me he ocupado en mi trabajo sobre "La génesis del poder de la banca". L. OrdunA, 2003, (pp. 589-621) 


\subsection{Causas circunstanciales o desencadenantes de las crisis y fluctuaciones económicas}

Las "causas circunstanciales" o "desencadenantes" de cada fluctuación y crisis histórica particular son siempre distintas. Están vinculadas al momento histórico en el que cada crisis se desencadena.

De hecho, si repasamos someramente las crisis y fluctuaciones acaecidas en el siglo XX, nos damos cuenta de que:

1. La crisis de 1929 estuvo vinculada directamente a la doctrina del "laissez-faire" con la consiguiente "inacción del Estado" así como al "desmoronamiento del patrón-oro"15. Todo lo cual llevó (fascismo y nazismo incluidos) a la Segunda Guerra Mundial.

2. Después de la Segunda Guerra Mundial, la crisis capitalista más importante ha sido la de los años 70 y 80 , cuyo hecho desencadenante se produjo el 15 de agosto de 1971 cuando el presidente Richard Nixon decretó unilateralmente la no convertibilidad del dólar en oro y la consiguiente "ruptura" de los pactos de Bretton Woods (constituidos en 1944) que habían dado origen al orden económico posterior a la Segunda Guerra.

Este hecho fue seguido por la crisis del petróleo y la estanflación de los años 70 y 80 . Y se saldó con la aparición de una "deuda impagable de los países del tercer mundo" con respecto al primer mundo. De la forma incorrecta en que se saldó la crisis de los setenta (sobre la que volveremos más adelante) provienen precisamente, las lacras del hambre, la pobreza y el subdesarrollo que azotan hoy a más de $2 / 3$ de la humanidad.

3. La crisis desencadenada a mediados de los años 90 y principios de la década de 2000, llamada crisis asiática, tiene una especial importancia porque puede considerarse el preludio de la crisis actual. Tuvo una naturaleza eminentemente financiera. Arrancó de Japón y se trasladó a todo el sudeste asiático afectando a Corea del Sur, Indonesia, Singapur y Tailandia, etc. Posteriormente la crisis pasó a otras áreas, como Turquía, Unión Soviética, e lberoamérica, especialmente, Argentina. Las monedas de los países afectados sufrieron una enorme devaluación y su producto bruto retrocedió entre quince y veinte años.

\footnotetext{
${ }^{15}$ Una explicación detallada del concepto de dinero y del papel que juega el mismo en el sistema capitalista, como consecuencia del sistema de crédito de la banca privada, puede encontrarse en mi trabajo sobre "La génesis del poder de la banca". Véase L. ORDUNA, 2003, (pp. 589-621)
} 


\section{Causas desencadenantes de la crisis iniciada en 2007-2008}

Además de las causas estructurales que son comunes a todas las crisis y fluctuaciones económicas que caracterizan al modelo capitalista, a las que nos hemos referido en el epígrafe anterior (básicamente: lucro máximo, arbitrariedad del poder y competitividad institucionalizada), el origen de la crisis desencadenada en 2007-2008 guarda íntima relación y tiene su antecedente histórico en la forma en que se saldó la crisis de los años 70 y 80 , así como en los hechos que se han sucedido desde entonces.

\section{I. Los problemas irresolutos de la deuda internacional}

La crisis de los 70 y 80 se saldó con una "deuda impagable" contraída por el tercer mundo con respecto a la banca del primer mundo ${ }^{16}$. La génesis de este proceso se inició cuando los gobiernos de los países desarrollados, para superar la recesión de los años 70 motivada por la caída del patrón-dólar-oro de 1944 (Pactos de Bretton Woods) y la subsiguiente alza de precios del petróleo, comenzaron a aplicar intensas políitcas anti-cíclicas dirigidas a incrementar sus exportaciones. Con este fin la gran banca internacional facilitó enormes sumas de crédito a países del tercer mundo, que eran prácticamente insolventes, adquiriendo éstos una deuda de grandes dimensiones que resultó imposible de pagar a sus vencimientos ${ }^{17}$.

Cuando, en la década de los 80 los bancos privados más importantes del mundo, especialmente los norteamericanos, empezaron a sufrir el impago de la deuda del tercer mundo (Méjico en 1982), los gobiernos de los países acreedores convinieron en aplicar distintas políticas de ayuda directa a los sistemas bancarios nacionales. Concretamente, la Reserva Federal y el gobierno de los Estados Unidos idearon el "plan Baker, J.", de 1985, que facilitó ingentes cantidades de liquidez al sistema bancario norteamericano, propugnando, con el fin de salvar los bancos, una refinanciación y un alargamiento de los plazos de vencimiento de las deudas impagadas, a poder ser con garantías públicas de los países deudores o, en otro caso, mediante la transformación de la deuda en activos empresariales situados en dichos países (caso de Chile).

\footnotetext{
${ }^{16}$ Para centrar el estudio del problema de la deuda del tercer mundo contraída en los años 70 y 80 del pasado siglo, propongo la lectura de Historia económica del siglo XX: integración europea e integración mundial, $2011-a$, L. ORDUNA (pp.282-300).

17 Para un mayor detalle puede verse, a este respecto, L. ORDUNA, 2011-a, (pp. 284 a 298).
} 
Como el plan Baker no consiguió la solución definitiva a los problemas de la deuda, el nuevo Secretario del Tesoro norteamericano, Nicholas Brady, propuso en 1989 que el Fondo Monetario Internacional tomara un papel más activo como Agente re-financiador de la deuda, exigiendo ajustes drásticos en la política económica llevada a cabo por los gobiernos de los países deudores. La administración y la banca norteamericanas consiguieron una devolución parcial de los créditos, mediante las ayudas prestadas por el Fondo Monetario Internacional a algunos países deudores, (esto motivó algunas reticencias del Fondo, en las que ahora no podemos entrar).

El "plan Brady" contribuyó muy activamente, durante los años 90, a que los bancos acreedores pudieran superar la crisis, pero no sirvió para dar salida a la situación en relación con los países deudores, pues, en definitiva, tanto el problema del "paro obrero" creciente, como el de la "deuda" internacional impagable y el "subdesarrollo" han resultado insolubles en el contexto económico del modelo actual internacional. Hoy los países pobres cada vez son más pobres y los ricos cada vez más ricos y el problema no hace sino agravarse continuamente, mientras los gobiernos responsables de los países ricos hacen muy poco para impedir la continuidad de este proceso.

Las políticas monetarias y presupuestarias practicadas por los países industrializados no fueron suficiente para solucionar definitivamente el problema de la deuda, por lo que la mayoría de los gobiernos de los países desarrollados, principalmente Estados Unidos, países de la Comunidad Europea y Japón decidieron, desde mediados de los 90, una completa "liberalización de los movimientos de capitales", que unida al "sistema de cambios libremente fluctuantes" (acuerdos de Jamaica de 1976), determinó un ahondamiento en la situación de "desregulación financiera mundial", que había sido iniciada en los años 80 como un camino para la salida de la crisis.

Durante las dos décadas siguientes se produjo una considerable extensión del crédito internacional entre países ricos resultante de los procesos de recuperación económica y de la expansión del comercio mundial, con una entrada sorprendente de China e India en el escenario de los intercambios internacionales, acentuada por las altas tasas de crecimiento del producto interior bruto. Asimismo tuvo lugar un creciente proceso de inversiones y movimientos de capitales, de carácter internacional, vinculado a la "transnacionalización industrial" y a las "privatizaciones", llevadas a cabo por los entes públicos empresariales o productivos de muchos países desarrollados, cuyos gobiernos necesitaban liquidez. Todo lo cual, junto con el "crecimiento demográfico" y el uso masivo de nuevos procedimientos 
informáticos y telemáticos en las transacciones, contribuyó a una multiplicación de las operaciones financieras en un volumen sin precedentes que se vio facilitado y acelerado como consecuencia de la utilización de nuevos instrumentos y productos financieros de carácter especulativo (cuyo contenido no siempre fue transparente, sino, muchas veces, opaco y falto de contenido real).

\subsection{La corrupción del sistema y el estallido de la crisis}

El resultado de los procesos anteriores fue lograr (a mi juicio no por casualidad) una dilución de los créditos impagados en el contexto de la banca mundial. Así fue como un cierto oscurantismo sobre cuál era la realidad de los estados financieros de muchas de las principales entidades bancarias e industriales del mundo, se adueñó del ambiente, dando lugar al afloramiento de numerosos casos de "corrupción". (Casos Enron, Arthur Andersen, Bilbao Vizcaya Argentaria, Gescartera, Parmalat, Fininvest, Forum Filatélico y otros similares en Inglaterra, Francia y Alemania, etc.)

Desde finales de los 90, gran parte de la banca privada internacional (los bancos privados suelen ser sociedades anónimas con ánimo de lucro máximo) se ha dedicado a desarrollar actividades insanas, enormemente especulativas, cuando no claramente abusivas y fraudulentas, a través de las llamadas "hipotecas sub-prime" y la puesta en circulación de activos financieros derivados de carácter "tóxico y opaco" con el consentimiento (o la "vista gorda", no se olvide) de las autoridades públicas monetarias (Gobiernos, Bancos Centrales, Reserva Federal etc.) de todo el mundo, que han practicado durante tres décadas una política muy laxa y, a mi juicio, totalmente irresponsable ${ }^{18}$.

\footnotetext{
${ }^{18}$ Según J. E. Stigutz, gran parte de la culpa de esta situación mundial se debe al papel erróneo y tendencioso jugado por el FMl, que sigue las directrices del Departamento del Tesoro norteamericano. Cree J. E. Stigutz, (Premio Nobel de economía, Presidente del Consejo Asesores del Presidente Clinton y Vicepresidente-economista-jefe del Banco Mundial) que: El efecto neto (juzgado en perspectiva histórica de los últimos 30 años,-este paréntesis es mío-) de las políticas estipuladas por el llamado Consenso de Washington (caracterizadas por políticas de estabilización monetaria y presupuestaria, de liberalización de los mercados y de los movimientos de capitales así como por las privatizaciones) ha sido favorecer la minoría a expensas de la mayoría, a los ricos a expensas de los pobres" y esto en detrimento del "medio ambiente, la democracia, los derechos humanos y la justicia social. (J. E. StIGLTZ, 2002, pp., 46). Para corroborar sus tesis, Stiglitz expone de manera extensa el caso de Rusia en su transición hacia el capitalismo desde el viejo comunismo. (StIGLITZ, J. E, 2002, pp., 86 y 88). Por contraposición, para explicar el camino que debería haber sido seguido en el caso ruso, explica cómo se está llevando a cabo la transición de China al capitalismo, poniendo de manifiesto que las pautas de racionalidad, prudencia y ritmo están siendo las adecuadas y su imitación, salvando las
} 
El aldabonazo se produjo el 14 de septiembre de 2008, con la quiebra del banco de negocios norteamericano Lehman Brothers, que fue seguida por la insolvencia (muchas veces definitiva, aunque ocultada a la opinión pública) de numerosos otros bancos en América y Europa, entre los que se cuentan varios de los más importantes del mundo, como el Bank of América, el Citibank, el ING de Holanda, Fortis de Bélgica, Societé General de Francia y diversos bancos ingleses, así como importantes entidades de comercialización de productos hipotecarios (Funny-MAE y Freddy-Mac), y la aseguradora norteamericana AIG (principal aseguradora del mundo en activos hipotecarios).

Los gobiernos, especialmente el norteamericano, como ya ocurriera en los años 80 , para evitar la quiebra de sus bancos privados más importantes afectados por una creciente desconfianza de los cuentacorrentistas, se vieron en la necesidad de intervenir para evitar que el sistema se derrumbara de una forma estrepitosa. Este derrumbamiento se hubiera producido, sin duda, si hubiera cundido el "pánico" y los depositantes hubieran acudido a las entidades bancarias masivamente para retirar sus depósitos. En efecto, como es sabido los depósitos bancarios, en gran parte son depósitos derivados y no dinero legal, de modo que el encaje bancario en dinero legal sólo cubre una parte de dichos depósitos derivados. El coeficiente de caja aplicado por las autoridades monetarias de los distintos países a sus entidades crediticias, puede oscilar entre márgenes muy amplios (desde el uno o $2 \%$ hasta el $100 \%$ ). Es una cuestión legislativa. Nosotros para nuestros cálculos hemos utilizado un coeficiente de caja aproximado del 15 al 20\%, que resulta bastante conservador, porque los coeficientes reales de encaje bancario suelen ser más bajos ${ }^{19}$. El hecho cierto es que, si todos los depositantes hubieran acudido masivamente a retirar sus depósitos, solamente una pequeña parte (en nuestro cálculo un quinto o sexto aproximadamente) hubiera podido recibir los fondos en forma de dinero legal, con lo que se hubiera producido una situación caótica en el

distancias, podría servir de pauta de implementación de otras políticas de tránsito desde los países subdesarrollados hacia el desarrollo. (STIGLTZ, J. E, 2002, pp., 67-74 y 81-125). Hay que decir, sin embargo, que China tiene una rémora fundamental en tanto en cuanto no respeta los derechos humanos fundamentales, practicando a este respecto una política dictatorial y tiránica.

19 Recientemente las autoridades monetarias intentan fortalecer la solvencia de los bancos mediante un reforzamiento de sus recursos propios en relación a sus pasivos totales. Puede verse en Internet "acuerdos de Basilea III". Esto ha motivado también una reforma de todo el sistema crediticio español, especialmente en el subsector de las CAJAS DE AHORROS, las cuales han dejado de ser, por lo general, FUNDACIONES, sin ánimo de lucro, para convertirse en SOCIEDADES ANÓNIMAS. Ha sido, a mi juicio, una reforma muy lamentable y entiendo que totalmente inadecuada para dar solución a los verdaderos problemas económicos en juego. No podemos extendernos más aquí, pero sin duda estamos ante decisiones de gran trascendencia que merecen ser tratadas más en un libro que en un artículo. 
sistema de pagos y el consiguiente derrumbamiento del "sistema de organización económica mundial".

\subsection{Las consecuencias de la crisis y los problemas de fondo}

Al estallar la crisis, rápidamente, todos los gobiernos pusieron en funcionamiento diversas fórmulas para garantizar los depósitos de los particulares por parte del Estado. Países, como Irlanda y Holanda, etc, garantizaron el 100 por 100 de los depósitos. España, a través del Fondo de Garantía de Depósitos (FGD) incrementó la garantía anteriormente establecida en $30.000 \leqslant$ por cuenta corriente hasta 100.000€. Otros países, como Inglaterra, acordaron temporalmente la nacionalización de algunos bancos privados. Otros bancos, en Estados Unidos, fueron directamente intervenidos por las autoridades públicas. En otros países se incrementó el capital con cargo al erario público.

En estas circunstancias, no es extraño que los especuladores bancarios, cuyo móvil es el máximo lucro, hayan aprovechado su enorme poder derivado del hecho de que la quiebra de un gran banco puede arrastrar la quiebra de todo el sistema financiero y bancario para chantajear a los gobiernos y a la sociedad. Así, la inyección de liquidez en el sistema bancario (con nuevos fondos legales a favor de las entidades especuladoras, mal gestionadas patrimonialmente) que, en las crisis suelen efectuar las autoridades económicas de los distintos países tratando de evitar la catástrofe que significaría el derrumbe del sistema financiero, son utilizados por estas mismas entidades para hacer pingües ganancias lucrativas y especulativas de nuevo. De este modo resulta que las mismas entidades causantes de la crisis, que inicialmente habían utilizado los fondos de manera irregular, logran hacer enormes ganancias por segunda vez con los nuevos fondos líquidos prestados por el Banco Central o el Estado y sus distintos organismos.

Se trata, pues, de una situación en la que el contribuyente, "paga doblemente las consecuencias de la crisis": En primer lugar se ha producido el "enriquecimiento de los especuladores bancarios" con el "paralelo empobrecimiento de la población" mediante el apalancamiento de operaciones especulativas y, después, cuando se ha producido la explosión de la burbuja especulativa creada se acude al Estado para que "salve a las entidades bancarias", con cargo de nuevo al "contribuyente".

Finalmente, el Estado, para financiar estas enormes operaciones de salvamento bancario y cubrir los cuantiosos gastos sociales adicionales que la recesión lleva consigo, se ha visto obligado a emitir "deuda pública adicional" en cantidades 
ingentes. En situaciones de recesión el "déficitpúblico" suele estar desbocado debido a la falta de ingresos públicos y a la simultánea obligación pública de atender a las necesidades sociales más perentorias. Para corregir el déficit, el Estado se ve obligado a suprimir gastos públicos de todas clases, reduce los salarios de sus funcionarios y deja caer el poder adquisitivo de las pensiones generales, cierra organismos y servicios públicos e incrementa los impuestos.

Por su parte la BANCA, desde el principio del estallido de la crisis ha dejado de conceder crédito al sector productivo privado, especialmente a la pequeña y mediana empresa, y se ha dedicado preferentemente a financiar deuda pública, por lo general más rentable y segura que las actividades privadas en tiempos de crisis. De este modo, la banca y el gobierno están contribuyendo activamente a acelerar la recesión y el cierre de empresas a través del efecto "crowding out" o "efecto expulsión sobre las inversiones privadas", lo que lleva a un creciente aumento del cierre de las empresas más pequeñas, las cuales precisamente eran las que mayor volumen de población ocupaban, produciendo así un notable incremento del "desempleo". La reducción de las actividades y de las ventas de las empresas privadas, obliga al gobierno a dar facilidades adicionales de despido ${ }^{20}$ hasta llegar a una situación caracterizada por el "paro masivo", en la terminología keynesiana. En definitiva, el salvamento de la banca privada se produce mediante el empobrecimiento general de la población y del contribuyente, resultando un beneficio final para ciertos accionistas o capitalistas, que encuentran salvada su propiedad.

Como ocurrió en todas las crisis anteriores, la actual se saldará con una gran recesión que empezó en 2008 y durará más de un "lustro" (y puede que dos o tres lustros, dependiendo de la política económica nacional e internacional que se haga). Como todas las crisis, la actual afecta de un modo más intenso a las

20 Conviene recordar que el trabajo no es una mercancía y, por consiguiente, la estructura de las relaciones laborales, en general, no debería estar sometida a las leyes del mercado y de la oferta y la demanda, como si fuera una simple mercancía. La organización del trabajo debería obedecer a una estructura en la que tuvieran primacía las decisiones dirigidas al bien común sobre las dirigidas a beneficiar la estructura lucrativa del capital. Y, en este sentido a mi juicio, más importante que la llamada reforma laboral que ha tenido lugar en España (orientada a abaratar el despido) hubiera sido, el establecimiento de una reforma del estatuto jurídico-económico de la empresa capitalista para corregirla en sus fundamentales defectos (falta de orientación hacia el pleno empleo, el exceso de ánimo de lucro y abuso de la posición de poder) y sus consecuencias, tanto en lo que afecta sus decisiones estratégicas de inversión (muchas veces mediatizadas por prácticas irregulares) como en lo que afecta a la forma de apropiación del excedente conjunto resultante, en una medida evidentemente mayor que la que en justicia debería corresponder al capital. Al lector interesado en un estudio en profundidad de esta cuestión le invito a la lectura de mi trabajo Empresa XXI: hacia la definición de un nuevo modelo empresarial, L. ORDUNA, 2010-b. 
capas sociales más débiles, generando "graves desequilibrios" en el "empleo" y en la "distribución de la renta y la riqueza" tanto a nivel nacional interno, como sobre todo a nivel internacional2 ${ }^{21}$.

Conviene hablar claro, la actual crisis no ha significado otra cosa que la materialización de un "gran fraude" fundamentado en el afán de lucro capitalista por parte de las entidades privadas financieras con forma de sociedades anónimas (no se olvide) y con la vista gorda de los gobiernos, con el agravante de un enorme apalancamiento financiero de carácter especulativo, con grave riesgo para los depositantes, consentido todo ello de modo inadmisible por los Bancos Centrales.

Según nuestros propios cálculos, en total el agujero o desfalco producido en las finanzas mundiales puede estimarse en alrededor de 15 billones de \$, la quinta parte del PIB mundial. Este dato se ha visto corroborado recientemente en unas declaraciones formuladas por Jean Claude Trichet, presidente del Banco Central Europeo, en las que afirma que el agujero o desfalco producido por la banca mundial, principalmente europea y norteamericana asciende, aproximadamente, al $27 \%$ del producto bruto conjunto de EE UU y la Unión Europea. (J. C. TRICHET, 2011, p.30).

En conclusión, los gobiernos y autoridades monetarias, junto a la banca privada son los principales responsables de lo ocurrido. Lo más grave es que todo induce a pensar que la actual crisis se va a "cerrar en falso" $y$, por tanto, volverá a repetirse en breve si cabe con una virulencia mucho mayor. En tal caso, es muy posible que, dada la cada vez mejor información general, la población por miedo a la pérdida de sus depósitos bancarios, acuda a retirarlos masivamente. Pero, si este hecho se produce y cunde el "pánico internacional", la consecuencia puede ser la destrucción y el desmoronamiento definitivo del "actual sistema capitalista mundial".

\footnotetext{
${ }^{21}$ Quiero recordar que, precisamente, algunas voces autorizadas habían previsto esta crisis y los riesgos en que estábamos incurriendo. Así, el Director General del Fondo Monetario Internacional, Rodrigo Rato Figaredo (en declaraciones hechas en el Colegio de Economistas de Madrid, en noviembre de 2006) avisó que se había producido una fuerte expansión de la liquidez mundial, señalando que: Los activos líquidos mundiales que en el 2000, sumaban el 81\% del PIB mundial, habían pasado en 2006 a representar el $137 \%$ de dicho PIB. A ello se añade que los activos líquidos derivados a nivel mundial (que incluyen depósitos bancarios a la vista y a plazos cortos) se calculaban en 285 billones \$, lo que equivaldría a seis veces el PIB mundial. Incluso el Papa Juan Pablo II había denunciado ya este problema en 1999 (Discurso a la Fundación Centesimus Annus Pro Pontífice, el 11.09.99) insistiendo en: La falta de correlación entre "estructura económica real" y "estructura económica financiera", advirtiendo de la necesidad de instituir una "autoridad mundial" capaz de controlar y corregir este grave problema.
} 


\section{La necesidad de una reorganización del sistema: medidas básicas}

No podemos dejarnos ofuscar por la perentoriedad y la urgencia en la resolución de algunos problemas más inmediatos de carácter financiero, (verdaderamente importantes como los desajustes del sector público, las irregularidades en el estado patrimonial de la banca y los desequilibrios del sector exterior), porque de lo que verdaderamente se trata es de encontrar las soluciones para el principal problema, que es el "desempleo". Hemos de tener en cuenta que el mayor sufrimiento de la población viene ocasionado por el "desempleo", pero junto a él, está el hecho de que mientras no se produzca una recuperación de las actividades económicas ninguno de los desequilibrios mencionados, incluido el fundamental del desempleo, podrá encontrar vías de solución. Por ello, la mejor forma de afrontar todos estos problemas consiste, a mi juicio, en diseñar un "plan" que los integre en un diagnóstico certero, tanto a "largo plazo" como a "corto plazo" para, después, aportar las soluciones escalonadas que todo ello requiere.

Las medidas que les voy a proponer a continuación van en esta dirección.

\section{I a "Reforma del estatuto jurídico-económico de la empresa", especialmente de la "empresa bancaria"}

El papel que está jugando la banca en la crisis actual nos lleva a reflexionar sobre las dos cuestiones adicionales siguientes:

Primera.- Los bancos hoy por hoy y con carácter general son, normalmente, entidades privadas con forma de "sociedades anónimas" con "ánimo de lucro máximo".

Segunda.- Los bancos tienen, en el sistema capitalista, un "especial poder de creación de dinero cuasi-legal", a través de los "depósitos derivados" y lo que los economistas llamamos el "proceso de expansión múltiple de los activos y pasivos bancarios". Según esto, el dinero bancario en forma de depósitos es, por lo general, un múltiplo del dinero legal en circulación ${ }^{22}$.

22 Según las declaraciones de 2006, antes citadas, hechas por Rodrigo Rato Figaredo, a la sazón Director Gerente del Fondo Monetario Internacional, los activos líquidos derivados en circulación a nivel bancario mundial se calculaban en aproximadamente seis veces el producto bruto mundial. 
Y pregunto: ¿La sociedad democrática puede confiar la enorme responsabilidad de ser creador de dinero cuasi-legal a una sociedad anónima, que actúa exclusivamente para el lucro propio, como es la banca privada?

Decididamente, no. Por tanto, no parece razonable que el legislador democrático deje la administración del crédito y la creación de dinero que corresponde a la banca al albur del lucro particular de sociedades anónimas puramente lucrativas $^{23}$, en perjuicio del bien general y común así como con grave riesgo para los depositantes y para el sistema económico general y mundial.

De ahí que, como "primera medida" hayamos de proponer una "profunda reforma legislativa" del "estatuto jurídico y económico de la empresa bancaria". Esta reforma, además, puede ser extraordinariamente importante porque se podría extrapolar a todas las empresas dominantes en los distintos sectores de actividad económica con forma de sociedades de capital. Y este cambio, en la medida que habría de suponer un cambio trascendental en la política de empleo, en las políticas de inversiones y precios de las empresas y en la política de crédito del sector bancario, podría ser el embrión de otro cambio más importante que afectaría a la propia estructura del sistema capitalista ${ }^{24}$. Evidentemente, además, sería un cambio ordenado y no un cambio caótico, como el que se habría de derivar si se produjera una crisis de pánico bancario mundial como la que hemos mencionado anteriormente.

Ha de recordarse que un modelo correcto de empresa prototipo" o "ideal", no debe ser concebido, como hoy lo hace el derecho mercantil, esto es, como si se tratara de:

\footnotetext{
${ }^{23}$ En mi libro sobre EMPRESA XXI: Hacia la definición de un nuevo modelo empresarial he sugerido la creación de entidades crediticias con forma de "mutualidad", en contraposición a las entidades con forma de "sociedades anónimas", lo que podría suponer importantes ventajas para el bien común. Véase L. ORduna, 2010-b, (pp. 91-93, 150-155, 265-277)

${ }^{24}$ Al estudio de un "modelo prototipo de empresa" he dedicado mi libro Empresa XXI: Hacia la definición de un nuevo modelo empresarial, a cuya lectura remito al lector interesado en conocer por qué el concepto de empresa utilizado por el modelo capitalista es erróneo y contribuye a agravar los problemas económicos fundamentales. Al mismo tiempo, en este libro se pone de manifiesto la concepción de otras formas de organización empresarial dirigidas a posibilitar cambios trascendentes para la mejor eficiencia y equidad del orden económico general y la forma de efectuar el tránsito desde el sistema capitalista a otro fundamentado en principios éticos.
} 
Un simple capital al que el derecho atribuye "personalidad jurídica" con la finalidad principal de acumular ganancias lucrativas en beneficio exclusivo y excluyente de los propietarios del capital.

El derecho positivo, a mi modo de ver, nunca debió conceder "personalidad jurídica" al capital, con independencia del trabajo.

La empresa no es sólo un capital, sino una simbiosis organizada de trabajo y capital, técnica y clientela yel derecho sólo puede conceder, en mi opinión, "personalidad jurídica" a este ente simbiótico cuando se dirija a facilitar un servicio a la sociedad en pro del bien común, (en cantidad, calidad y precio justo), haciendo partícipe en las ganancias y decisiones de la empresa de una forma equitativa tanto al trabajo como al capital y a la clientela así como a la sociedad en su conjunto y siempre con la mirada puesta en el bien común. Lo que no ha de ser óbice para que la empresa haya de tener las ganancias apropiadas que le permitan su propio desarrollo y sus mejoras tecnológicas de una manera ilimitada en el espacio y en el tiempo.

2a. "Corrección de las asimetrías" derivadas del "sistema de fijación de los precios e inversiones"

El desigual poder de las empresas en el sistema competitivo produce en los mercados "continuas desviaciones" sobre las inversiones y los precios, con respecto a los que deberían resultar de un correcto método de organización del sistema y de la adecuada valoración de los bienes y servicios.

Hoy, la "valoración de los bienes y servicios" que se comercializan en el sistema está basada en la ley de la oferta y la demanda así como en la competitividad y el lucro máximo, a partir de poderes desiguales de influencia sobre el mercado. Como consecuencia, los conglomerados empresariales resultantes soslayan el "modo lógico de fijación de los precios" que derivaría de una recta valoración de los bienes y servicios en forma de "escandallos", esto es, una valoración construida mediante un proceso técnico que tuviera en cuenta el valor de los componentes (técnica y organización, mano de obra, materias primas y capital) necesarios para la elaboración del bien o servicio en cuestión y que condujera al "precio justo" de todos los intercambios bajo un prisma de objetividad y equilibrio racional.

La tendencia hoy dominante lleva a un sistema caracterizado por el "poder omnímodo" de los "monopolios" y los "grupos económicos de mayor tamaño". Y esto no es extraño, porque si el objetivo de la empresa es el lucro máximo, independientemente del bien común, la estructura resultante habrá de ser la de una tendencia generalizada hacia los monopolios que es lo que hoy ocurre en la realidad. 
Se constituye así un método de valoración que refuerza la "primacía del capital sobre el trabajo" en toda clase de intercambios, lo que está en la base de los "errores conceptuales" de los que partió Adam Smith para concebir el sistema de organización económica actual dando "primacía en las conductas al principio del lucro sobre el principio del bien común". Este sistema hace "caso omiso" de la verdadera "naturaleza creativa del trabajo" 25 .

De estos "errores conceptuales" derivan todos los demás, como el postulado de la pretendida "primacía del principio de la escasez sobre el principio del progreso" en la que se basa la teoría económica dominante de la oferta y la demanda y el de la pretendida "primacía del principio de la competitividad sobre el principio de la cooperación" en que se apoya el sistema competitivo de los intercambios. Estos errores, y las asimetrías que conllevan, dan lugar a "teoremas equivocados" que están en la base de la mayor parte de los desequilibrios del sistema capitalista a los que antes me he referido.

El sistema también hace "caso omiso" del objetivo esencial de organización a que todo sistema económico viene llamado, en cuanto a su obligación de facilitar a todos los sujetos una "igualdad de oportunidades" y un "empleo" como medio de garantía de la supervivencia de cada persona. Esta obligación y garantía (derecho fundamental no se olvide) ha de cumplirse so pena de que el propio "sistema de concurrencia" pierda toda "legitimidad".

De ahí que, como "segunda medida" hayamos de proponer una profunda reforma del "sistema de fijación de los precios" en los mercados, estableciendo precios de referencia o indicativos obtenidos en forma de escandallos y precios justos para corregir los desequilibrios y asimetrías característicos de los mercados actuales. Por otra parte esta medida debe llevar también a una modificación de la estructura de las "inversiones empresariales privadas" y a una clarificación del carácter selectivo que han de tener siempre las inversiones públicas, en aras al "bien común" que es su fin.

\footnotetext{
${ }^{25}$ A este respecto, quisiera recordar lo que ya en el año 1986, el entonces Cardenal Ratzinger, hoy Papa Benedicto XVI tuvo ocasión de señalar, afirmando: La transformación del orden social debe empezar por un gran esfuerzo de educación y debe continuar con la promoción de una verdadera civilización del trabajo... donde ha de ser emprendida de manera prioritaria una acción liberadora,... dando prioridad al trabajo sobre el capital rechazando la concepción del trabajo como simple mercancía... y teniendo en cuenta que el derecho de propiedad privada no es concebible sin unos deberes con miras al bien común. Véase R. DE LA ClerVA, 1986, (p.535).
} 


\section{3a. "Revisión del paradigma actual de la ciencia económica" y la "aplicación de uno nuevo de carácter ético"}

Con lo anterior, llegamos a la "tercera medida" que tiene que ver con la idea de que la "ciencia económica ortodoxa", además de incurrir en graves incoherencias, no ha sido capaz de resolver los problemas fundamentales que le incumbían, particularmente los de organizar un sistema con plena ocupación del trabajo, la eficiente creación de riqueza y la equitativa distribución de esa riqueza para el desarrollo de todos los hombres y pueblos de un modo acorde con la "justicia social".

Ha de observarse que, a la hora de "concebir un sistema de organización económica fundamental", sólo existen dos opciones partiendo de la libertad, según que, a su vez, incluyamos o no el principio ético como elemento inherente a los "móviles" de la conducta y de la libertad. Así, desde el plano teórico podemos distinguir:

1. En primer lugar, "el enfoque actual" dominante, que es "a-ético", esto es, un orden económico fuera y al margen de la ética.

Este enfoque se corresponde, precisamente, con el "modelo capitalista", el cual, partiendo del principio de libertad, sitúa ésta libertad al margen del principio de la justicia y la equidad, pretendiendo hacer del "interés propio exclusivista" o "lucro máximo", el "móvil" de todas las conductas con vistas a que el "principio de competitividad" bajo la "ley de la oferta y la demanda" llegue a ser el "modelo" de un "supuesto equilibrio", aunque con resultados claramente "injustos" en la distribución de la renta y la riqueza. A este modelo no le interesa la justicia ni la equidad. Sólo está interesado en el "lucro máximo" y la pretendida "acumulación de ganancias" que derivará del "interés propio exclusivista".

2. Y por otra parte, el "enfoque ético", esto es, un orden económico que hace de la ética su núcleo fundamental ${ }^{26}$.

Este enfoque, partiendo igualmente del principio de libertad, situaría esta libertad bajo el principio de "equidad" compatible con un principio de "igualdad en lo fundamental" (derechos y deberes fundamentales conforme a la dignidad humana) y compatible con el principio de "libertad responsable" que dimana

\footnotetext{
${ }^{26}$ A esta cuestión, ya tuve ocasión de referirme hace más de 25 años en un trabajo publicado en la Revista de Fomento Social al tratar de las relaciones entre "Ética y Desarrollo económico", a cuya lectura remito al lector interesado. Véase L. Orduna, 1986, n 162 (abril-junio), pp. 183-193.
} 
igualmente de esa misma dignidad. El modelo habría de conducir, así, a un equilibrio económico caracterizado por la "cooperación" y la "justa y equitativa distribución de la renta", haciendo del "bien común compatible con el interés propio legítimo" el "móvil" de todas las conductas.

Nuestra propuesta va en la dirección de esta segunda opción. Así, un "sistema", construido bajo el enfoque ético, no sólo ha de ser equitativo, por definición conceptual, sino que ha de ser también "el más eficiente" de entre los concebibles, porque, requiere inexorablemente una "organización previa", fundamentada en la <<plena vigencia de los derechos humanos fundamentales>> (que garantiza la igualdad básica), el <<pleno empleo de los recursos y de la población >> (que garantiza la eficiencia) y la <<primacía del trabajo sobre el capital >> (que garantiza la equidad y la libertad creativa).

Y, sobre estas bases, el sistema habrá de "funcionar" como un proceso institucional dirigido a lograr el "precio justo" de todos los "intercambios" y orientado a dirigir las inversiones hacia la "desaparición de las lacras de la pobreza, el hambre y el subdesarrollo", fácilmente eliminables con una programación masiva de las inversiones a escala mundial. Piénsese que con una pequeña parte de lo utilizado para salvar a la banca se hubiera podido solucionar el problema del hambre en el mundo y se hubiera podido colocar a los países más pobres en vías de su propio desarrollo autónomo. Se podría haber logrado, en definitiva, una estructura organizativa dirigida al "desarrollo equitativo de la riqueza y de la renta" que hubiera embarcado a toda la humanidad en un modelo de convivencia común.

En conclusión, podemos afirmar que un cambio en la estructura organizativa de la convivencia política, económica, jurídica y social en la que el elemento ético apareciera en el centro de todas las decisiones, no sólo habría de dar lugar a la estructura más justa y efectiva desde el punto de vista del orden racional, sino también habría de ser la más beneficiosa a corto, medio y largo plazo para todos los elementos, sujetos y organizaciones involucradas ${ }^{27}$.

27 "El progreso histórico y la economía del desarrollo", objeto de análisis en un trabajo publicado en la Revista de Fomento Social, con ese mismo título. Véase ORDUNA, L., 1988, n 170 (abril-junio), pp. 165-178. 


\section{$4^{a}$. "Profundas reformas legislativas y constitucionales" para hacer "vigentes los derechos humanos fundamentales".}

Los cambios que acabo de proponer no se podrán lograr sin un "sistema jurídicoconstitucional" que unifique y coordine todas las democracias. En este sentido, lo mejor sería que todos los gobiernos acordaran converger hacia un "modelo democrático universal" aceptable por todos y "auténticamente participativo", con una verdadera división de poderes y un legislador justo y universal. Un modelo, donde los "representantes" puedan ser cesados en cualquier momento por sus "representados" y donde las corrupciones se hicieran prácticamente imposibles.

Las reformas legislativas requieren también la "convergencia de todas las culturas" hacia una "ética común". Esto, ha de significar, finalmente, que todos los países admitieran la idea de transferir partes crecientes de su "soberanía nacional" a una "autoridad común" bajo el frontispicio del "respeto a los derechos humanos". La meta última sería llegar a un "sistema constitucional universal", perfectamente justo, en los términos expuestos por el filósofo Emmanuel Kant hace ya más de 200 años $^{28}$.

Por eso tenemos que adquirir conciencia plena de que el "sistema social" en que vivimos, por irreductible que parezca, es obra humana conformada en el proceso histórico, estructurado por la mano del hombre. No hay una "mano invisible para regir el mundo" (de la que nos hablaba Adam Smith), sino unas manos de poder bien visibles: la banca privada, los gobiernos con todas sus instituciones y las grandes empresas transnacionales, principalmente.

En este sentido, en el siglo XXI la humanidad debe abandonar el paradigma del "lucro máximo individual" y la "competitividad" sobre la base del "abuso de poder" que ha dominado la estructura económica mundial durante más de dos siglos, para entrar en una nueva era ética que abrace la "cooperación" y la "justicia" como cimientos de la "democracia" y de la "libertad".

${ }^{28}$ A este respecto Kant afirma: El problema mayor del género humano, a cuya solución le constriñe la Naturaleza, consiste en llegar a una sociedad civil que administre el derecho en general. Y prosigue: El problema de la institución de una constitución civil perfecta depende, a su vez, del problema de una legal relación exterior entre los Estados, y no puede ser resuelto sin éste último. Y concluye: Se puede considerar la historia de la especie humana en su conjunto como la ejecución de un secreto plan de la Naturaleza, para la realización de una constitución estatal interiormente perfecta, y, con este fin, también exteriormente, como el único estado en que aquella puede desenvolver plenamente todas las disposiciones de la humanidad. E. KANT, (1984). pp. 48, 52 y 57. 
Esto significa tanto como decir que la "actual globalización liberal-capitalista" habrá de trocarse en una "globalización ético-económica", donde la libertad de movimientos de las personas y la justicia social así como la organización del orden económico y del trabajo esté sólo fundamentada en la "dignidad humana".

Parece obvio concluir, que el orden constitucional tiene en este proceso un papel importante que jugar, tanto en lo político como en lo económico y, por supuesto, en lo jurídico. Si el "sistema constitucional" omite regular derechos fundamentales de los ciudadanos o regula esos derechos y luego los hace inoperantes por falta de un desarrollo legislativo subsidiario, veremos cómo se rompe el equilibrio y el mismo "modelo constitucional" se convertirá en un semillero de discordias.

El pleno empleo y la estructura del sistema de trabajo, o el salario y sus componentes, - la educación adecuada y la igualdad de oportunidades, o la cobertura de las necesidades más perentorias, o la atención ante las situaciones catastróficas o la estructura de la empresa y su concepto o los sistemas de control de las instituciones públicas o privadas de interés general o los delitos de los gobernantes por lesa democracia o las formas de gobierno político y participación democrática en la vida socio-económica, etc., así como la persecución y sanción de los abusos de poder, de los despilfarros y de las corrupciones deben estar claramente regulados en el "ordenamiento jurídico y constitucional".

\section{6. ¿Cómo podrían comenzar a hacerse viables hoy los cambios constitucionales necesarios?}

Permítaseme sugerir, una idea al respecto. Tomando como instrumento las "constituciones nacionales democráticas", quizás podríamos convenir en que las naciones democráticas podrían acordar, en cada país, la institucionalización de UN "ÓRGANO" "AD HOC" expresamente dedicado a cumplir con la finalidad de proponer la transformación de la propia constitución de cada país para instaurar un "orden universal" de carácter democrático que facilitase la convergencia y la integración económica y política mundial, sobre la base del efectivo cumplimiento de los Derechos Humanos Fundamentales. Es decir, cada Estado democrático podría crear en su seno un "Consejo Nacional", con el mismo nombre y objetivos en todos los países, que pudiera funcionar conforme a un régimen estatutario idéntico en el ámbito de todas las naciones: El Consejo Nacional para la Universalización de la Participación Democrática y la Integración Mundial. 
Las aparentes dificultades para llevar a la práctica esta idea pueden ser fácilmente superadas en el momento en que los actuales partidos políticos tomen conciencia de que de esta exigencia democrática puede depender su propia subsistencia futura y que, en todo caso, esta subsistencia habrá de estar sometida a un duro proceso de reestructuración democrática en adelante. Hoy, los partidos políticos no funcionan como instituciones verdaderamente democráticas, sino como oligarquías. Por eso, los partidos políticos actuales deben ser conscientes de que, en caso de no adaptarse a los cambios éticos que requiere la democracia participativa y universal se verán obligados a desaparecer ante el impulso de los ciudadanos para lograr el cambio social requerido, que incluye cotas mayores, mucho mayores, de "justicia social" y de "participación". De ahí, que la función esencial de los partidos políticos, hoy, haya de consistir en contribuir a la transformación social y democrática, incluso, en detrimento del propio interés partidista, por supuesto.

El citado Consejo sería un órgano nuevo, del máximo rango en cada Estado democrático, que coexistiría con los demás altos órganos del Estado. Pero que tendría como misión la de preparar, impulsar y, una vez decidida por referéndum, materializar la auto-transformación de cada Constitución nacional para hacer posible la elaboración de ese "orden político y económico mundial" que se hace preciso erigir, tomando como frontispicio la "Declaración Universal de Derechos del Hombre" de la propia ONU.

Con la misma finalidad, podría constituirse, también, UN ÓRGANO "AD HOC" EN EL SENO DE LA ONU que podría ser denominado "Consejo Mundial para la Universalización de la Participación Democrática y la Integración Mundial" (C.U.P.D.I.M.), constituido por todos los "Consejos Nacionales". La ONU, a su vez, podría crear una "Secretaría Constitucional" como órgano "ad hoc", de carácter permanente, que pudiera servir para dar apoyo administrativo a este "Consejo Común".

No se nos escapa, por último, que habría que ser muy cuidadoso para evitar el "riesgo" de que estos "consejos" cayeran en la "corrupción" (tan extendida, incluso, en los llamados países democráticos). Una forma de evitar este peligro podría consistir en dar a cada "Consejo Nacional" un rango máximo constitucional que permitiera que sus miembros fueran elegidos mediante "sufragio directo y universal" entre personas de reconocido prestigio con conocimientos suficientes y con absoluta independencia de los "partidos políticos".

Además, cada uno de los componentes de este Consejo estaría facultado para actuar tanto individualmente como colegiadamente con arreglo al dictado de su "conciencia", conforme al "estatuto" del que el propio Órgano se habría dotado. 


\section{Referencias Bibliográficas}

BENEDICTO XVI (2009) Caritas in veritate www.vatican.va/holy

BlAUG, M. 1980. La metodología de la economía. Madrid, Ed. Alianza.

Castaño Piñan, A. (1981). Introducción de la obra de Kant: "Por qué no es inútil una nueva crítica de la razón pura". Buenos Aires, Ed. Aguilar.

CIERVA, R. de la (1986) Jesuitas, Iglesia y Marxismo: la teología de la liberación desenmascarada, Barcelona, Ed. Plaza y Janés.

DillaRD, D. (1973) La teoría económica de J.M. Keynes, Madrid, Ed. Aguilar.

EUCKEN, W. (1967) Cuestiones fundamentales de Economía Política, Madrid, Ed. Alianza.

Ferrater Mora, J. (1992) Diccionario de filosofía,. Madrid, Ed. Alianza.

GAlBRAITH, J.K. (1972) El capitalismo americano, Barcelona, Ed. Ariel.

Gimbernat, J.A. (1997) "De la utopía a la realidad de los Derechos Humanos" en Diario El Mundo de 10-12-97. Madrid.

Gonzalez Carvajal, L. (1996) Fieles a la tierra, Madrid, Ed. Edice.

Gonzalez Perez, J. (1986) La dignidad de la persona, Madrid, Ed. Civitas.

GoROSQUIETA, J. (1985) "Decisión económica de invertir y destino ético del beneficio". Comunicación presentada al congreso de F.I.U.C. (Federación Internacional de Universidades Católicas), Bruselas, Ed. Universidad de Lovaina.

HaBERMAS, J. (1981) "Problemas de legitimación del Estado moderno" en La reconstrucción del materialismo histórico, Madrid, Ed. Taurus.

HAYEK, F.A. (1982) Los fundamentos de la libertad, Madrid, Ed. Unión Editorial.

HoBBES, T. (1979) Léviathan, Madrid, Ed. Nacional.

Iglesia Católica (I.C.) (1992) Catecismo, Madrid, Ed. Asociación de editores.

ImAZ, E. (1984) "Prólogo" en Kant, E. (1984) Filosofía de la Historia, Madrid, Ed. F.C.E. 
JuAN Pablo II (1988) Sollicitudo Rei Socialis (Preocupación por los problemas sociales), Madrid, Ed. Paulinas.

JuAN XXIII. (1992) "Pacem in terris" en Once grandes mensajes, Madrid, Ed. B.A.C. $14^{\mathrm{a}}$ edición.

Kant, E. (1981). Por qué no es inútil una nueva crítica de la razón pura, Buenos Aires, Ed. Aguilar.

- (1984) Filosofía de la Historia, Madrid, Ed. F.C.E.

- (2005) Metafísica de la costumbre, Madrid, Ed. Tecnos.

KEYNES, J.M. (1971) Teoría general del empleo, el interés y el dinero, Madrid, Ed. F.C.E.

Kinder, H. y HilgemanN, W. (1991) Atlas histórico Mundial, Madrid, Ed. Itsmo.

KUHN, T.S. (1983) La tensión esencial, México, Ed. F.C.E.

LINDE, E. (1988) Constitución y Tribunal Constitucional, Madrid, Ed. Civitas.

LuCAS Verdu, P. (1989) Curso de derecho político, Madrid, Ed. Tecnos.

- (1990) Manual de Derecho político, Madrid, Ed. Tecnos.

Maheu, R. (1982) "Prefacio" en Piaget y otros Tendencias de la investigación en las ciencias sociales, Madrid, Ed. Alianza.

Malthus, T. R. (1977) Principios de economía política, México, Ed. F.C.E..

MARIAS, J. (1995) Tratado de lo mejor, Madrid, Ed. Alianza.

MARTIN, V. (1990) Naturaleza humana y orden económico, Madrid, Ed. U.C.M. Fac. CC.EE. y EE.

- (1991) La ética y la economía en Adam Smith, Madrid, Ed. Facultad de Ciencias. Económicas y Empresariales. Dpto. de Historia Económica I. Universidad Complutense.

MarX, C. (1973) El capital, (Vol. I, II y III), México.Ed. F.C.E. 
Marx, C. y Engels, F. (1974) El manifiesto comunista, Madrid. Ed. Ayuso.

MEDINA, M. (1974) La Organización de Naciones Unidas: estructura y funciones, Madrid, Tecnos.

MiLL, J. S. (1984) El Utilitarismo, Madrid, Ed. Alianza.

- (1985) Principios de Economía Política y Filosofía Social, México, Ed. F.C.E.

Moro, T. (1998) Utopía, Madrid, Ed. Il. Colegio de Abogados de Madrid.

Myrdal, G. (1966) Solidaridad o desintegración, México, Ed. F.C.E..

- (1979) Teoría económica y regiones subdesarrolladas, México, Ed. F.C.E..

- (1973) Reto a la pobreza, Barcelona, Ed. Ariel.

- (1978) "Significado y validez de la economía institucional" en La economía del futuro. Hacia un nuevo paradigma, México, Ed. F.C.E..

NiCOL, E. (1974) Los principios de la ciencia, México, Ed. F.C.E..

ONU-PNUD (1999) Informe sobre Desarrollo Humano, Madrid, Mundi Prensa.

ORduna, L. (1986) "Ética y Desarrollo Económico", en Revista de Fomento Social, n 162, (abril-junio), pp. 183-193.

- (1988) "El progreso histórico y la economía del desarrollo", en Revista de Fomento Social, no 170 (abril-junio), pp. 165-178.

- (2003) "La génesis del poder de la banca", en Estudios de historia y del pensamiento económico: homenaje al profesor Bustelo García del Real, pp. 589 a 621, Madrid. Ed. Complutense.

- (2005a) Análisis estructural de los modelos de desarrollo económico, Madrid, Ed. CERSA.

- (2005b) Los Fundamentos de la Economía Política y la ldea de Orden Económico, Madrid, Ed. CERSA.

- (2006) El desafío económico del Japón, Madrid, Ed. CERSA. 
- (2007) "Las ideas de Keynes para el orden económico mundial", en Revista de Economía Mundial, n 16.

- (2010-a) Economía y Antropología Ética, Madrid, Ed. CERSA.

- (2010-b) Empresa XXI: Hacia la definición de un nuevo modelo empresarial, Madrid, Ed. CERSA.

- (2010-c) "Ciencia económica y escasez: clarificación de conceptos" en Revista del Ilustre Colegio de Economistas de Madrid. ECONOMISTAS, $\mathrm{n}^{\circ}$ 125, pp. 101-116.

- (2011-a) Historia Económica del Siglo XX: Integración europea e integración mundial, Madrid, Ed. CERSA.

- (2011-b) Estructura Económica y Desarrollo: El Tránsito hacia una Reorganización del Sistema, Madrid, Ed. CERSA.

Ortega y Gasset, J. (1967) ¿Qué es filosofía?, Madrid, Ed. Arquero.

- (1981) La historia como sistema, Madrid, Ed. Alianza.

Perez de AyAlA, J.L. (1976) Introducción a una Teoría pura de la Economía política, Madrid, Ed. Edersa.

Piaget, J. y otros. (1982) Tendencias de la investigación en las ciencias sociales, Madrid, Ed. Alianza.

RATZINGER, (1986) "Instrucción sobre libertad cristiana y liberación" (publicado con el título "La verdad os hará libres"), Diario $A B C, 5$ de Abril.

RaWLS, J. (1986) Justicia como equidad, Madrid, Ed. Tecnos.

RoBBiNs, L. (1952) An essay on the nature and significance of economic science, London, Macmillan $C^{\circ}$.

RoBBINS, L. (1980) Ensayo sobre la Naturaleza y significación de la Ciencia Económica, México, Ed. F.C.E..

Rodriguez-Arana, J. (1996). Etica institucional, Madrid, Ed. Dykinson.

Rojo, L.A. (1984) Keynes: su tiempo y el nuestro, Madrid, Ed. Alianza. 
RÖPKE, W. (1955) Introducción a la Economía Política, Madrid, Ed. Rev. Oc.

SAMPEDRO, J.L. (1973) Estructura económica, Barcelona, Ed. Ariel.

SAN Agustin (1964) "Enarrationes in Psalmos XXXIX, 7" en Obras completas de San Agustín, Madrid, Ed. B.A.C.

Sanchez Agesta, L. (1974) Curso de derecho constitucional comparado, Madrid, Ed. Facultad de Derecho de la Universidad de Madrid.

Sanchez de la Torre, A. (1965) Sociología del Derecho, Madrid, Ed. Rev. D. Priv.

SAÑA, H. (1967) El capitalismo y el hombre, Madrid, Ed. Edicusa.

SCHUMPeter, J.A. (1982) Historia del análisis económico, Barcelona, Ed. Ariel.

SEN, A., (1989) Sobre ética y economía, Madrid, Ed. Alianza.

- (1995) Nuevo examen de la desigualdad, Madrid, Ed. Alianza.

- (1997) Bienestar, justicia y mercado, Barcelona, Ed. Paidós.

SISMONDI, S., (1969) Economía política. Madrid, Ed. Alianza.

SMITH, A. (1955) Una investigación de la naturaleza y causas de la riqueza de las naciones, Barcelona, Ed. Bosch.

- (2005) An Inquiry into the Nature and Causes of the Wealth of Nations, Ed. Pennsylvania State University.

Stigutz, J. E. (2002) El malestar en la globalización, Madrid, Ed. Taurus.

TINBERGEN, J., (1970) Hacia una Economía Mundial, Barcelona, Ed. OIKOS-TAU.

- (1977) Reestructuración del orden internacional, México, Ed. F.C.E..

TRICHET, J-C., (2011) "Sección de economía" del diario EL PAíS, sábado 14 de mayo 2011 , p.30.

VeCCHIO, G., (1969) Filosofía del Derecho, Barcelona, Ed. Bosch. 